\title{
Correction to: Four-Body Bound-States Systems in Relativistic Scalar Quantum Field Theory: Variational Basis-State Approach
}

\author{
Mohsen Emami-Razavi ${ }^{1} \cdot$ Marian Kowalski $^{2} \cdot$ Somayeh Asgary ${ }^{3}$ \\ Published online: 4 December 2019 \\ (C) Springer Science+Business Media, LLC, part of Springer Nature 2019
}

Correction to: Int J Theor Phys (2018) 57:2989-3004.

https://doi.org/10.1007/s10773-018-3818-z

The author found a mistake in their published article. There is an "and" missing between "Science" and "Research Branch" in the affiliation. The correct affiliation address of the first author (Mohsen Emami-Razavi) is:

Plasma Physics Research Center, Science and Research Branch, Islamic Azad University, Tehran, Iran.

The online version of the original article can be found at https://doi.org/10.1007/s10773-018-3818-z

Mohsen Emami-Razavi

mrazavi@srbiau.ac.ir

1 Plasma Physics Research Center, Science and Research Branch, Islamic Azad University, Tehran, Iran

2 University of Ontario Institute of Technology, 2000 Simcoe Street North, Oshawa, ON L1H 7K4, Canada

3 Department of Physics, West Tehran Branch, Islamic Azad University Tehran, Tehran, Iran 